\title{
Communication
}

\section{White-Light GaN- $\mu$ LEDs Employing Green/Red Perovskite Quantum Dots as Color Converters for Visible Light Communication}

\author{
Xiaoyan Liu ${ }^{1}{ }^{\circledR}$, Langyi Tao ${ }^{1}$, Shiliang Mei ${ }^{2}{ }^{\circledR}$, Zhongjie Cui ${ }^{2}$, Daqi Shen ${ }^{1}$, Zhengxuan Sheng ${ }^{1}$, Jinghao Yu ${ }^{1}$, \\ Pengfei Ye ${ }^{1}$, Ting Zhi ${ }^{1}$, Tao Tao ${ }^{3}$, Lei Wang ${ }^{1, * \mathbb{D}}$, Ruiqian Guo ${ }^{2, *}$ and Pengfei Tian ${ }^{2, *}$
}

Citation: Liu, X.; Tao, L.; Mei, S.; Cui, Z.; Shen, D.; Sheng, Z.; Yu, J.; Ye, P.;

Zhi, T.; Tao, T.; et al. White-Light GaN- $\mu$ LEDs Employing Green/Red Perovskite Quantum Dots as Color Converters for Visible Light Communication. Nanomaterials 2022, 12, 627. https://doi.org/10.3390/ nano12040627

Academic Editors: Mohammed Jaouad Meziani, Zhaohui Li and Wolfgang Heiss

Received: 12 January 2022 Accepted: 9 February 2022 Published: 13 February 2022

Publisher's Note: MDPI stays neutral with regard to jurisdictional claims in published maps and institutional affiliations.

Copyright: (C) 2022 by the authors. Licensee MDPI, Basel, Switzerland. This article is an open access article distributed under the terms and conditions of the Creative Commons Attribution (CC BY) license (https:// creativecommons.org/licenses/by/ $4.0 /)$.
1 College of Integrated Circuit Science and Engineering, and National and Local Joint Engineering Laboratory for RF Integration and Micro-Packaging Technologies, Nanjing University of Posts and Telecommunications, Nanjing 210023, China; xiaoyanliu@njupt.edu.cn (X.L.); b18020227@njupt.edu.cn (L.T.); b18020308@njupt.edu.cn (D.S.); b18012128@njupt.edu.cn (Z.S.); 1020021023@njupt.edu.cn (J.Y.); 1320027525@njupt.edu.cn (P.Y.); zhit@njupt.edu.cn (T.Z.)

2 Institute for Electric Light Sources, School of Information Science and Technology, Fudan University, Shanghai 200433, China; meishiliang@fudan.edu.cn (S.M.); 19110720020@fudan.edu.cn (Z.C.)

3 Key Laboratory of Advanced Photonic and Electronic Materials, School of Electronic Science and Engineering, Nanjing University, Nanjing 210046, China; ttao@nju.edu.cn

* Correspondence: leiwang1980@njupt.edu.cn (L.W.); rqguo@fudan.edu.cn (R.G.); pftian@fudan.edu.cn (P.T.)

Abstract: GaN-based $\mu$ LEDs with superior properties have enabled outstanding achievements in emerging micro-display, high-quality illumination, and communication applications, especially white-light visible light communication (WL-VLC). WL-VLC systems can simultaneously provide white-light solid-state lighting (SSL) while realizing high-speed wireless optical communication. However, the bandwidth of conventional white-light LEDs is limited by the long-lifetime yellow yttrium aluminum garnet (YAG) phosphor, which restricts the available communication performance. In this paper, white-light GaN- $\mu$ LEDs combining blue InGaN- $\mu$ LEDs with green/red perovskite quantum dots (PQDs) are proposed and experimentally demonstrated. Green PQDs (G-PQDs) and red PQDs (R-PQDs) with narrow emission spectrum and short fluorescence lifetime as color converters instead of the conventional slow-response YAG phosphor are mixed with high-bandwidth blue InGaN- $\mu$ LEDs to generate white light. The communication and illumination performances of the WL-VLC system based on the white-light GaN-based $\mu$ LEDs are systematically investigated. The VLC properties of monochromatic light (green/red) from G-PQDs or R-PQDs are studied in order to optimize the performance of the white light. The modulation bandwidths of blue InGaN$\mu \mathrm{LEDs}$, G-PQDs, and R-PQDs are up to $162 \mathrm{MHz}, 64 \mathrm{MHz}$, and $90 \mathrm{MHz}$ respectively. Furthermore, the white-light bandwidth of $57.5 \mathrm{MHz}$ and the Commission Internationale de L'Eclairage (CIE) of $(0.3327,0.3114)$ for the WL-VLC system are achieved successfully. These results demonstrate the great potential and the direction of the white-light GaN- $\mu$ LEDs with PQDs as color converters to be applied for VLC and SSL simultaneously. Meanwhile, these results contribute to the implementation of full-color micro-displays based on $\mu$ LEDs with high-quality PQDs as color-conversion materials.

Keywords: white-light GaN-based $\mu$ LEDs; perovskite quantum dots; visible light communication; solid-state lighting

\section{Introduction}

Group III-nitride semiconductors are among the most popular wide-bandgap semiconductors owing to their superior advantages of high electron mobility, wide bandgap, high stability, and high breakdown voltage [1-3]. The wide direct bandgap, ranging from deep ultraviolet $(\sim 6.2 \mathrm{eV})$ to near-infrared $(\sim 0.7 \mathrm{eV})$, can be tuned to span the entire UV and visible spectrum. Therefore, group III-nitride semiconductors have gathered enormous attention and undergone rapid development in varied applications of optoelectronics and 
power electronics such as light-emitting diodes (LEDs), laser diodes (LDs), photodetectors, high-electron-mobility transistors (HEMTs), and so forth [4-8]. Among them, GaN-based LEDs have become some of the most mature and influential optoelectronic devices since they were first demonstrated in the 1990s [9]. They have been widely used in solid-state lighting (SSL), outdoor and indoor displays, and backlight sources owing to their high efficiency and endurance, high cost efficiency, low power consumption, etc. [10-12]. More recently, micron-scale LEDs sized from $1 \mu \mathrm{m}$ to $100 \mu \mathrm{m}$, known as micro-LEDs ( $\mu$ LEDs), have become a favorite topic in academia and industry. In contrast with broad-area LEDs, GaN-based $\mu$ LEDs possess excellent electronic and optical properties including lower resistance-capacitance (RC) delay, high bandwidth, high efficiency, high brightness, and high contrast. Thanks to these outstanding characteristics, GaN-based $\mu$ LEDs have seen development beyond SSL, and are used in cutting-edge applications such as micro-displays, augmented reality and virtual reality, optogenetics, and visible light communications (VLC) [13-15]. In 2010, the GaN-based $\mu$ LED was first employed in VLC by Martin D. Dawson from the University of Strathclyde [16]. Since then, $\mu$ LEDs have attracted extensive attention and achieved dramatic advances in the VLC field [17-22].

As a promising candidate for next-generation wireless communication technology, VLC - particularly white-light visible light communication (WL-VLC), combining SSL and optical wireless communication together-has been pursued by the academic community and industry. Utilizing light as a data-transmission carrier, VLC possesses the advantages of a broad frequency range, high data rate, greater security, higher energy efficiency [23], and lack of radio frequency (RF) interferences. Due to the limited bandwidth and the crowded communication window of existing RF and microwave wireless communication technologies, a great deal of effort has been made to prove that VLC has an enormous potential to fulfill the surging demand for the informatization exchange of modern society. Commonly, the conventional white-light LEDs used for SSL consist of the blue light from a broad-area LED and the yellow light from YAG:Ce ${ }^{3+}$ phosphor. Nevertheless, the YAG:Ce ${ }^{3+}$ phosphor suffers from long photoluminescence (PL) lifetime and low modulation bandwidth (less than $20 \mathrm{MHz}$ ), showing limited capability for VLC [24,25]. With the peculiarities of high PL quantum yield, short PL lifetime, and narrow emission bandwidth, perovskite quantum dots (PQDs) present an appealing opportunity in next-generation lighting sources for both illumination and communication [26-31]. Dursun et al. utilized LDs to excite $\mathrm{CsPbr}_{3}$ perovskite nanocrystals and a conventional red phosphor to generate the white light for VLC [32]. Liang et al. synthesized the $\mathrm{CsPbBr}_{3}$ liquid perovskite quantum dots which were applied in an LD-based white-light VLC system [33]. The maximum transmitted data rates at a receivable bit error rate (BER) of two systems were up to 2 Gbps and 1 Gbps, respectively [32,33]. The LD-based VLC systems have outstanding performances in wireless communication, but are poor in the SSL field owing to problems such as limited etendue, detriment to human eyes, and speckle noise [34]. Therefore, light sources (such as LED) that are more acceptable for human eyes and the environment in the long term are desired. In contrast to broad-area LED, $\mu$ LEDs with a feature size of tens of micrometers enjoy excellent intrinsic properties such as larger current saturation density and higher modulation bandwidth $[19,35,36]$, revealing their enormous potential in both VLC and SSL fields. Leitão et al. set up a VLC system based on a $\mathrm{CsPb}_{4} \mathrm{Br}_{6}$ matrix with $\mathrm{CsPbBr}_{3}$ QDs and an InGaN $\mu \mathrm{LED}$, with a corresponding modulation bandwidth of up to $24.6 \mathrm{MHz}$ [37]. In our previous report, a high-bandwidth white-light system was proposed which consisted of yellow-emitting $\mathrm{CsPbBr}_{1.8} \mathrm{I}_{1.2}$ perovskite quantum dots and a blue GaN-based $\mu \mathrm{LED}$. The system has presented a high bandwidth of up to $85 \mathrm{MHz}$ and a maximum data rate of $300 \mathrm{Mbps}$ [38]. Although some progress has been made in WL-VLC, there is a trade-off between illumination performance and communication capacity, so it is important to balance high-quality lighting and high-speed communication. Therefore, many efforts need to be made to pursue high-quality white-light systems that can simultaneously implement high-quality SSL and high-capacity VLC dual-function applications. Several types of color 
converters have been explored for use as color-conversion layers to generate high-quality white light while maintaining high-bandwidth communication performance.

Hence, in this paper, green PQDs (G-PQDs) and red PQDs (R-PQDs) are employed as color converters, which are excited by blue InGaN- $\mu$ LEDs to produce the white light for SSL and VLC. The characteristics of monochromatic light (red/green) from G-PQDs and R-PQDs are studied to obtain high-quality illumination while maintaining high modulation bandwidth. The SSL properties and VLC performances of the obtained white-light system are further investigated in detail. In this study, the maximum $-3 \mathrm{~dB}$ modulation bandwidths of monochromatic light and white light were up to $\sim 64 \mathrm{MHz}$ (green-light), $\sim 90 \mathrm{MHz}$ (red-light), and $57.5 \mathrm{MHz}$ (white-light), respectively. Moreover, the white light generated by blue InGaN- $\mu$ LEDs, G-PQDs, and R-PQDs possessed a Commission Internationale de L'Eclairage (CIE) of $(0.3327,0.3114)$ and the color temperature of $5474 \mathrm{~K}$.

\section{Experimental Methods}

\subsection{Fabrication of In $\mathrm{GaN}-\mu L E D$ Device}

Blue-emitting InGaN- $\mu$ LEDs were fabricated from a commercial GaN epitaxy wafer grown on c-plane sapphire substrates. An n-GaN layer, an InGaN/GaN multiple quantum well (MQW) layer, an AlGaN electron blocking layer, and a p-GaN layer were deposited on the patterned sapphire substrates through metal-organic chemical vapor deposition.

A series of fabrication processes including photolithography, wet and dry etching, film deposition, lift-off, etc. were performed in a cleanroom. The following briefly describes the typical fabrication processes of the InGaN- $\mu$ LED, which is shown in Figure 1a. The $\mathrm{Ni} / \mathrm{Au}(10 \mathrm{~nm} / 25 \mathrm{~nm})$ metal was deposited as a current spreading layer by magnetron sputtering or electron-beam evaporation before fabrication of the InGaN- $\mu$ LED device. Next, utilizing inductively coupled plasma etching (ICP), the epitaxial structure was etched to the $\mathrm{n}-\mathrm{GaN}$ layer, and the $\mu$ LED mesa was manufactured. This was followed by rapid thermal annealing in nitrogen at $500{ }^{\circ} \mathrm{C}$ to form an ohmic contact. Then, a $290 \mathrm{~nm} \mathrm{SiO}{ }_{2}$ layer was deposited as a standard isolation layer by plasma-enhanced chemical vapor deposition (PECVD). Lithographic patterning and wet/dry etching processes were used to etch $\mathrm{SiO}_{2}$ to open apertures on the $\mu$ LED mesas and the n-contact area to deposit metal. Finally, via photolithography and metallization, the $\mathrm{Ti} / \mathrm{Au}(50 \mathrm{~nm} / 200 \mathrm{~nm})$ metal was deposited as n-track and p-track. The fabrication details can be found in previous work [19,35,38-42]. In this way, the $\mu L E D$ arrays with square and circular mesas and various sizes were fabricated successfully. The diameters for circular $\mu$ LED pixels were 40,60 , and $100 \mu \mathrm{m}$. For square $\mu \mathrm{LED}$ pixels, the side lengths were 40,60 , and $80 \mu \mathrm{m}$. The $2 \mathrm{D}$ epitaxial structure of a single square InGaN- $\mu$ LED is shown in Figure 1b. Figure 1c presents a 3D schematic diagram of the InGaN- $\mu$ LED arrays with square pixels.

\subsection{Fabrication of $\mathrm{GaN}$-Based White-Light $\mu \mathrm{LEDs}$}

GaN-based white-light micro-LEDs were fabricated by employing blue InGaN- $\mu$ LEDs as light sources and PQDs as the color converters. PQDs were synthesized through a modified hot-injection method based on a previous study [43]. Under a nitrogen atmosphere and at a reaction temperature of $150{ }^{\circ} \mathrm{C}, \mathrm{Cs}$-oleate solution was quickly injected into a mixture of octadecene, oleylamine, oleic acid, and $\mathrm{PbX}_{2}(\mathrm{X}=\mathrm{Br}$ or I). The as-prepared green $\mathrm{CsPbBr}_{3}$ QDs (G-PQDs) were extracted after discarding the supernatant. The red $\mathrm{CsPb}(\mathrm{Br} / \mathrm{I})_{3}$ QDs (R-PQDs) were fabricated in the same way. The fabricated G-PQDs and $\mathrm{R}-\mathrm{PQDs}$ were encapsulated in epoxy resin, which isolated them from oxygen and moisture. The detailed synthesis processes can be found in our previous study [38]. The prepared PQD films acting as color converters were overlaid on the blue-emitting InGaN- $\mu$ LEDs, and the white light was obtained under excitation of the $\mu$ LEDs. Then, the InGaN- $\mu$ LED chip covered with PQDs was bonded to a printed circuit board. Finally, the hybrid white-light GaN-based devices were implemented. 


\subsection{Construction of WL-VLC System}

As presented in Figure 1d, the main part of the VLC system consisted of blue InGaN$\mu L E D$, G-PQDs and R-PQDs, a transmitter lens (Tx lens), a receiver lens (Rx lens), and a photodetector. The blue-emitting $\mu L E D s$ were employed as light sources to excite different PQDs which could adjust the color component of light required by the VLC system. Using a non-return-to-zero on-off key (NRZ-OOK) modulation scheme, the signals were modulated to the $\mu$ LEDs by the bias tee. The modulated light propagated through the free-space transmission link. Color converters were put into the light path to fulfill the experimental requirements. The Tx lens and $\mathrm{Rx}$ lens were used to collimate and focus the modulated light generated from the light-emitter. The light was received and recorded by a photodetector, and then the light signals were converted to electric signals for further analysis of the frequency response, BER, and eye diagrams. Based on the above VLC link, a network analyzer (Agilent, N5225A, $10 \mathrm{MHz}-50 \mathrm{GHz}$ ) was used to measure the frequency response to obtain the modulation bandwidth under different currents. The BER was measured by an error-detector module built into the signal quality analyzer (Anritsu, MP1800A, 0.1-14 GHz). A wide-bandwidth oscilloscope (Agilent $86100 \mathrm{~A}, 14 \mathrm{GHz}$ ) was used to capture eye diagrams. All measurements were carried out at ambient temperature in air.

(a)

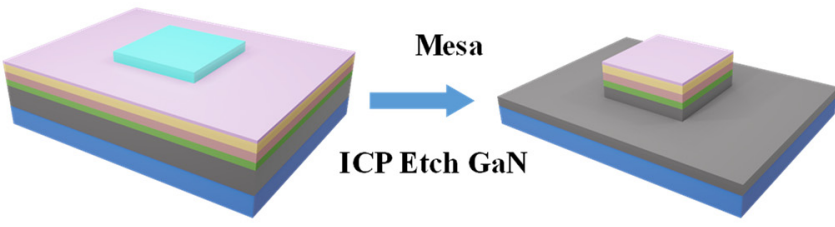

Photolithography
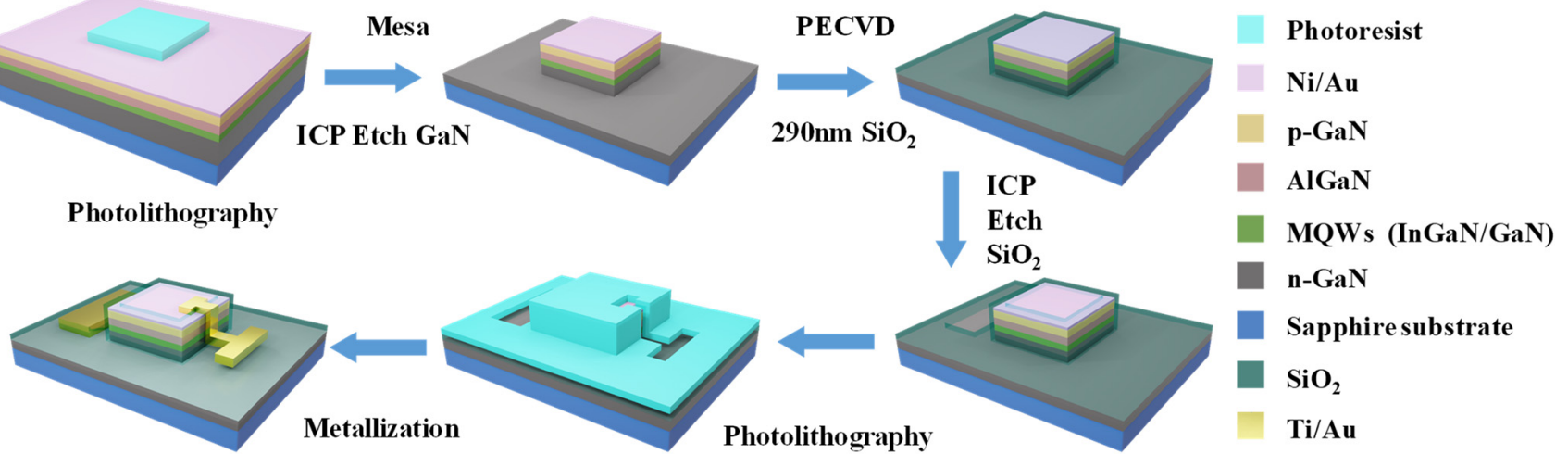

(b)

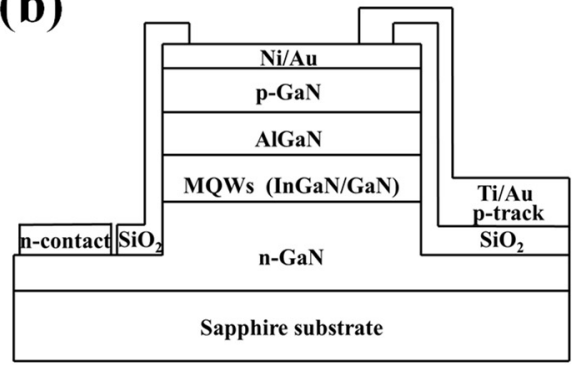

(c)

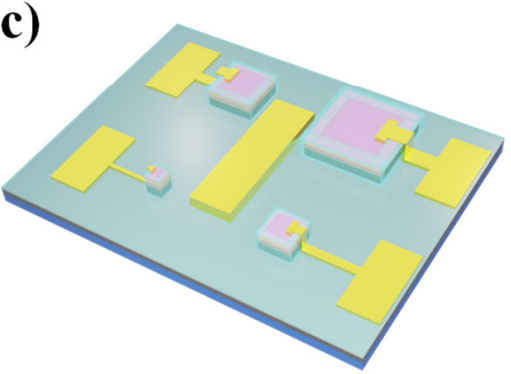

Etch $\mathrm{SiO}_{2}$

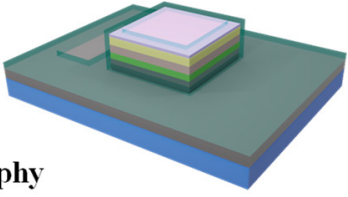

(d)

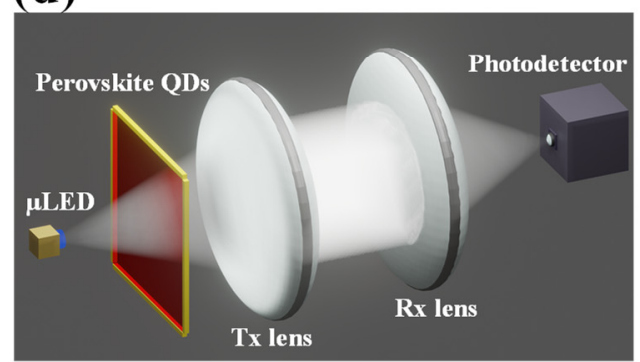

Figure 1. (a) The schematic diagram of the typical fabrication process and (b) the epitaxial structure of square InGaN- $\mu$ LED. (c) The 3D schematic diagram of square InGaN- $\mu L E D$ arrays with different sizes. (d) Schematic diagram of WL-VLC system based on the white-light GaN-based $\mu$ LED with PQDs as color converters.

\section{Results and Discussion}

\subsection{Electrical and Optical Properties of InGaN- $\mu L E D s$}

We studied the electrical and optical properties of the fabricated InGaN- $\mu$ LEDs before they were embedded into the system. The relationship between current density and bias voltage $(\mathrm{J}-\mathrm{V})$ and that between light output power and injection current (L-I) of circular $\mu$ LEDs with different diameters are illustrated in Figure 2. The figure indicates a dependent relationship between output performance and device scale. That is, the smaller the $\mu$ LEDs, the higher the current density that the $\mu$ LEDs could sustain, and a lower light output that the $\mu$ LEDs could produce. These results were in accordance with the J-V and L-I characteristics of the InGaN- $\mu$ LEDs with square pixels, as shown in Figure S1. Therefore, 
there was a trade-off between modulation bandwidth and light-output power, which will be discussed in the following section.
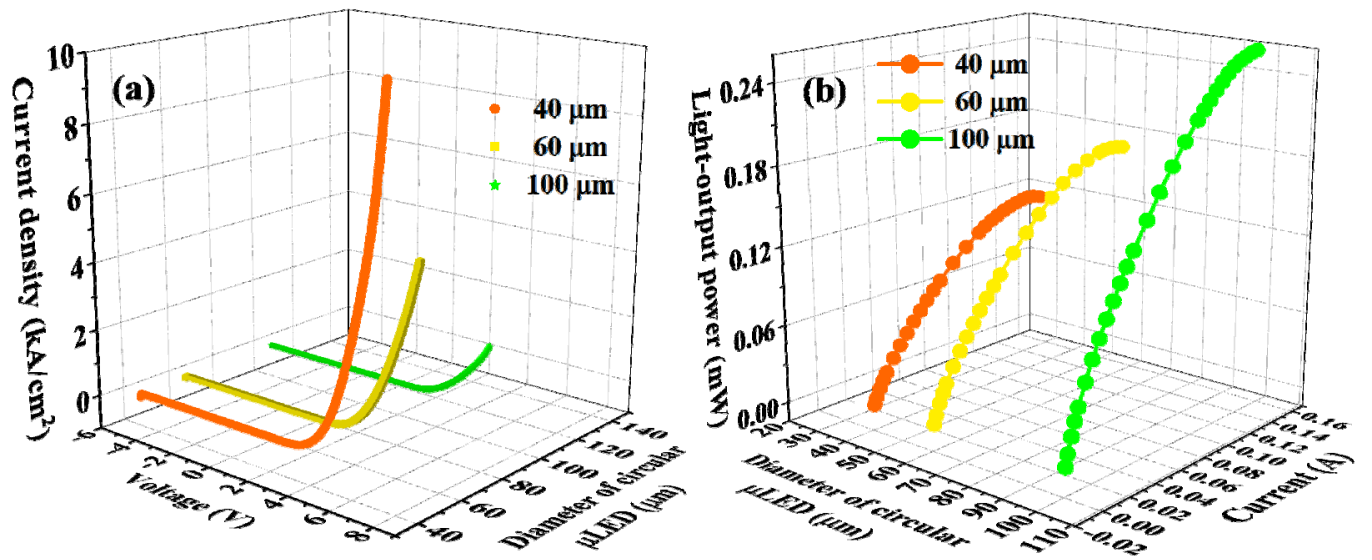

Figure 2. (a) J-V and (b) L-I characteristics of circular InGaN- $\mu$ LEDs with different diameters.

Figure 3 demonstrates the normalized electroluminescence (EL) spectra of the circular InGaN- $\mu$ LEDs, taking $80 \mu \mathrm{m} \mu \mathrm{LED}$ as an example. In Figure 3a, with increasing injection current, the peak wavelength of the EL spectrum moved to the shorter wavelength direction and the full width at half maximum (FWHM) increased, then both kept saturation. Both the movement of peak wavelength and the increase of FWHM were on a small scale, ensuring good monochromaticity for SSL. Figure $3 b$ shows the peak wavelength as a function of the injection current, which was extracted from Figure 3a. The blueshift of the emission wavelength observed is attributed to the carrier-screening effect of the quantum-confined Stark effect and/or the band-filling effect [44], which degrades the performance of $\mu$ LEDs (e.g., aging, reliability, and modulation bandwidth) $[45,46]$. As a result, to obtain optimal modulation bandwidth and light-output power, the appropriate working current was chosen to drive the $\mu$ LEDs. For InGaN- $\mu$ LEDs with square pixels, the EL spectra were similar to those of InGaN- $\mu$ LEDs with circular pixels, as shown in Figure S2.
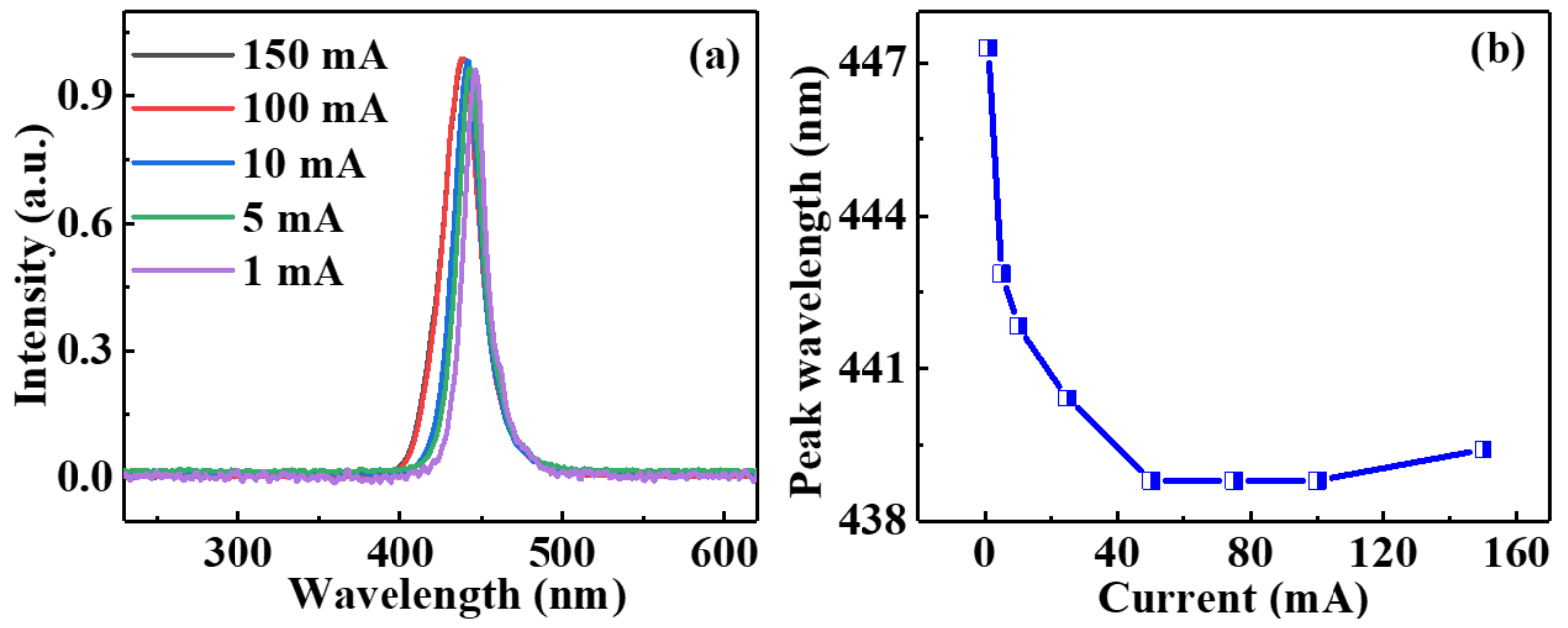

Figure 3. (a) The normalized EL spectra of circular $\mu L E D$ with a diameter of $80 \mu \mathrm{m}$ under different currents. (b) Peak wavelength extracted from the EL spectra at different injection currents.

\subsection{Frequency Responses of In $G a N-\mu L E D s$}

To study the modulation bandwidth of the InGaN- $\mu$ LED for high-speed VLC, we evaluated the normalized electrical-to-optical frequency response of the circular $\mu$ LEDs with different sizes under the injection current varying roughly in the region from approximately $0 \mathrm{~mA}$ ( $\sim$ hundreds of $\mathrm{nA}$ ) to $150 \mathrm{~mA}$ (Figure $4 \mathrm{a}-\mathrm{c}$ ). As shown in Figure 4a, with 
the increase of injection current, the modulation bandwidth first increased then saturated for the circular $\mu \mathrm{LED}$ with a diameter of $40 \mu \mathrm{m}$. In Figure $4 \mathrm{~b}, \mathrm{c}$, the characteristics of the modulation bandwidth versus injection current for circular $\mu$ LEDs with diameters of $60 \mu \mathrm{m}$ and $100 \mu \mathrm{m}$ were consistent with that of $40 \mu \mathrm{m} \mu \mathrm{LEDs}$ (Figure $4 \mathrm{a}$ ). The higher bandwidth was obtained at a higher current, which can be attributed to the reduced differential carrier lifetime at higher injection currents [42]. The bandwidth saturation might be attributed to the impedance mismatch between the $\mu$ LED and the package [39]. The highest bandwidths of $\mu$ LEDs with different sizes are shown in Figure $4 d$. It is evident that attainable modulation bandwidth increased as the size of the $\mu$ LEDs decreased, further indicating that InGaN- $\mu$ LEDs have greater potential in the field of VLC than broad-area LEDs. For InGaN- $\mu$ LEDs with square pixels, the frequency response of the $\mu$ LED with a side length of $80 \mu \mathrm{m}$ has been studied in previous work [38,39]. The change trend of bandwidth versus current was consistent with that of the e circular InGaN- $\mu$ LEDs.
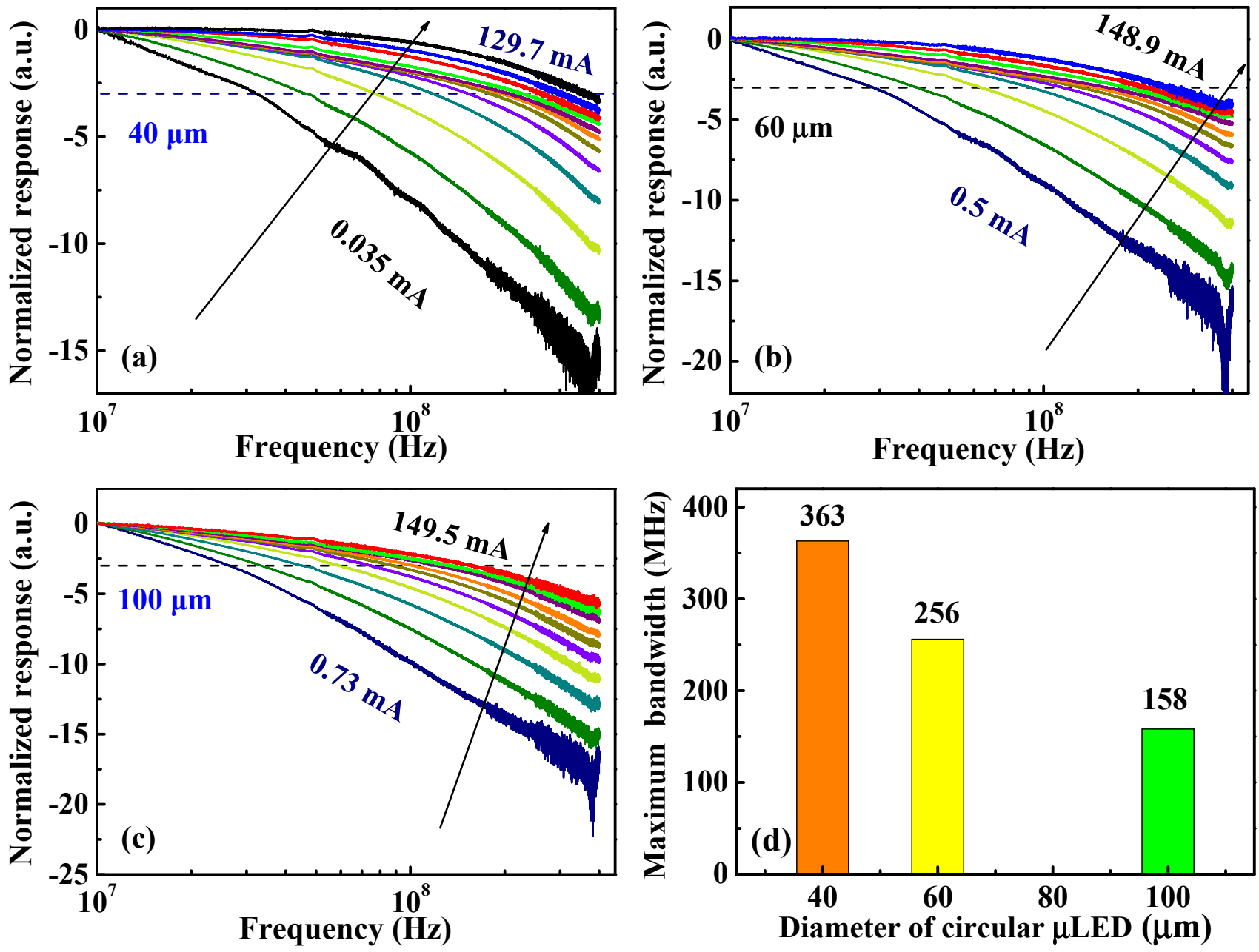

Figure 4. Frequency responses of the circular InGaN- $\mu$ LEDs with the diameters of (a) $40 \mu \mathrm{m}$, (b) $60 \mu \mathrm{m}$, and (c) $100 \mu \mathrm{m}$ under different injection currents. The $-3 \mathrm{~dB}$ modulation bandwidth is marked by a dashed line. (d) The maximum bandwidths of InGaN- $\mu$ LEDs with different sizes.

Although smaller $\mu$ LEDs possessed higher bandwidth (Figure 4), the output power was decreased owing to the smaller mesa area (Figure 2), leading to a higher BER that limits communication speed and transmission distance. In this work, the InGaN- $\mu$ LEDs as light sources excited PQDs and mixed them to generate white light for SSL and VLC, so a higher light-output power was desired. Comparing Figure $2 b$ with Figure S1b, it is evident that the square InGaN- $\mu \mathrm{LED}$ with the side length of $80 \mu \mathrm{m}$ had the maximum light-output power (up to $1.3 \mathrm{~mW}$ ) among the samples. In addition, note that in Figure S3, the square 
$\mu L E D$ with the side length of $80 \mu \mathrm{m}$ presented a maximum bandwidth bandwidth of about $162 \mathrm{MHz}$. Therefore, to balance the bandwidth of the $\mu$ LED for VLC and the light-output performance for the SSL, the square InGaN- $\mu$ LED with the side length of $80 \mu \mathrm{m}$ was applied for the WL-VLC system.

\subsection{Visible Light Communication and Solid-State Lighting}

Before the construction of the white-light system, two kinds of color-conversion materials (R-PQDs and G-PQDs) were utilized separately to generate monochromatic light for communication, and the properties of both PQDs are discussed in the following. Figure 5 a presents the spectrum of R-PQDs under excitation of the $\mu$ LED, where one peak wavelength was at $445 \mathrm{~nm}$ from the $\mu \mathrm{LED}$ and another peak wavelength was at $611 \mathrm{~nm}$ from R-PQDs. Likewise, the spectrum of G-PQDs excited by $\mu$ LED is shown in Figure $5 b$, with two peak wavelengths representing $\mu$ LED and G-PQDs at $445 \mathrm{~nm}$ and $531 \mathrm{~nm}$, respectively. The FWHMs of the R-PQDs and G-PQDs were $34 \mathrm{~nm}$ and $21 \mathrm{~nm}$, manifesting the outstanding narrow emission of PQDs.
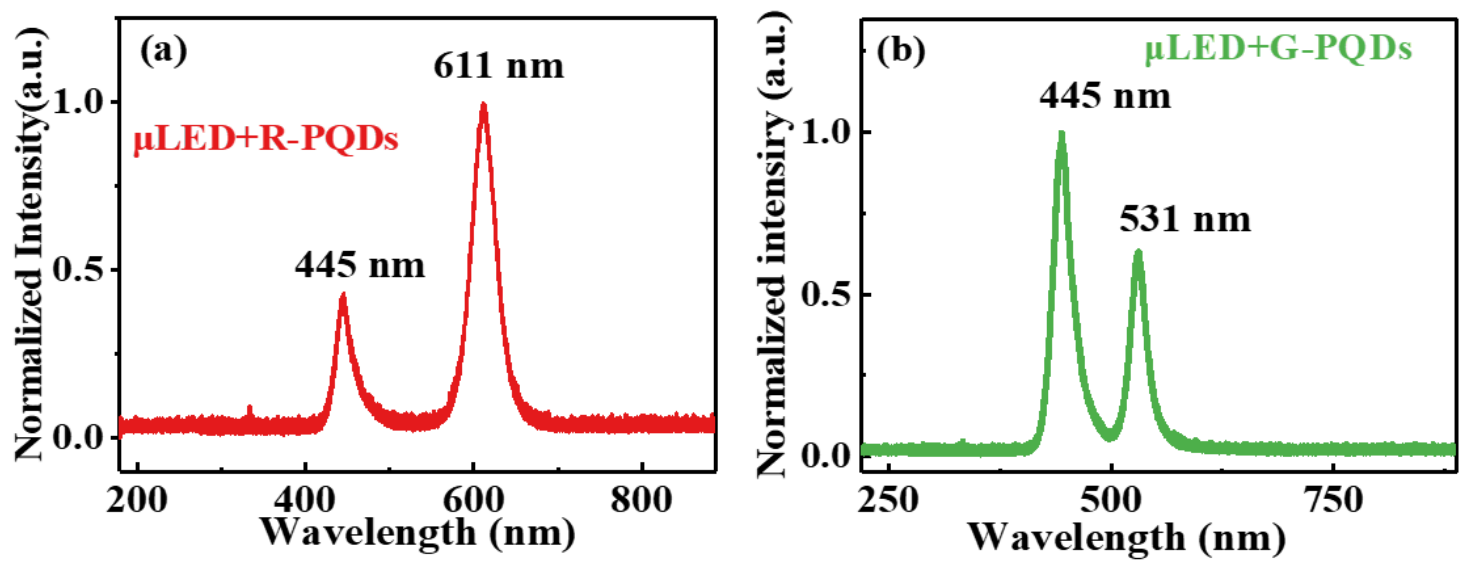

Figure 5. PL spectra of light generated by $\mu$ LEDs exciting two kinds of luminescent materials: (a) R-PQDs (b) and G-PQDs.

The normalized responses of R-PQDs and G-PQDs excited by the blue InGaN- $\mu$ LEDs were measured, which are exhibited in Figure 6 . The bandwidth of the square InGaN- $\mu$ LED with the size of $80 \mu \mathrm{m}$ was up to $\sim 162 \mathrm{MHz}$, and under the excitation of the $\mu \mathrm{LED}$, the bandwidths of R-PQDs ( $\mu$ LED + R-PQDs) and G-PQDs ( $\mu$ LED + G-PQDs) were $\sim 90 \mathrm{MHz}$ and $\sim 64 \mathrm{MHz}$, respectively. Meanwhile, the R-PQDs showed better stability and higher bandwidth than the G-PQDs as the curve declined more slowly and smoothly. The superiority of PQDs can be supported by drawing a comparison with the slow frequency responses of conventional YAG: $\mathrm{Ce}^{3+}$ phosphors (2.5 MHz) [25].

As shown in Figure 7a,b, the eye diagrams were measured at a data rate of $100 \mathrm{Mbps}$ for $\mu \mathrm{LED}+\mathrm{R}-\mathrm{PQD}$ and $\mu \mathrm{LED}+\mathrm{G}$-PQDs, respectively. Attributed to the higher frequency response and signal-to-noise ratio of the R-PQDs, the eye diagram is not only open and clear but also less noisy in comparison with that of the G-PQDs. The maximum data rate of the R-PQDs shown in Figure 7c was achieved at $200 \mathrm{Mbps}$ with a BER of $3.3 \times 10^{-3}$, beneath the forward error correction $(F E C)$ criterion of $3.8 \times 10^{-3}$. Similarly, in Figure $7 d$, the maximum achievable data rate of the G-PQDs system was $170 \mathrm{Mbps}$ with a BER of $3.5 \times 10^{-3}$, below the FEC threshold. Therefore, both R-PQDs and G-PQDs show excellent potential in optical wireless communication. 


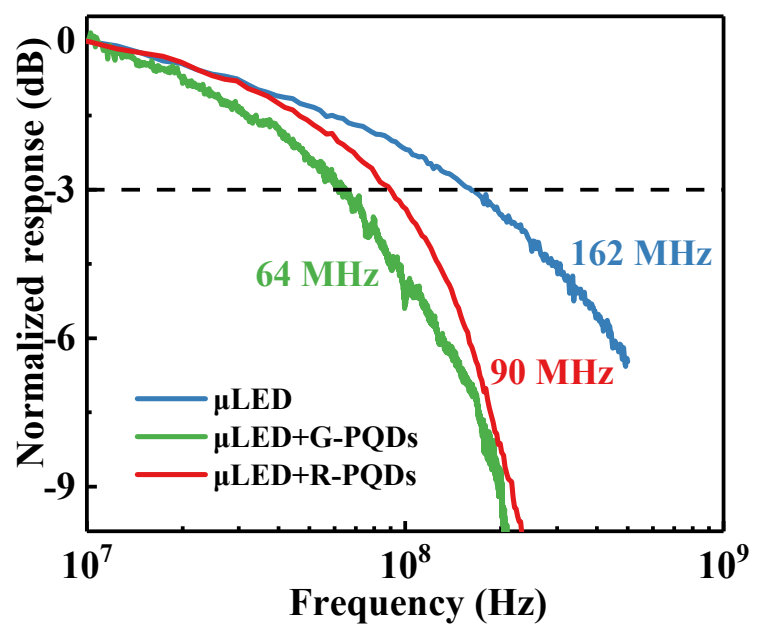

Figure 6. Frequency responses of the square $\mu \mathrm{LED}$, R-PQDs, and G-PQDs. The $-3 \mathrm{~dB}$ modulation bandwidth is marked by a dashed line.
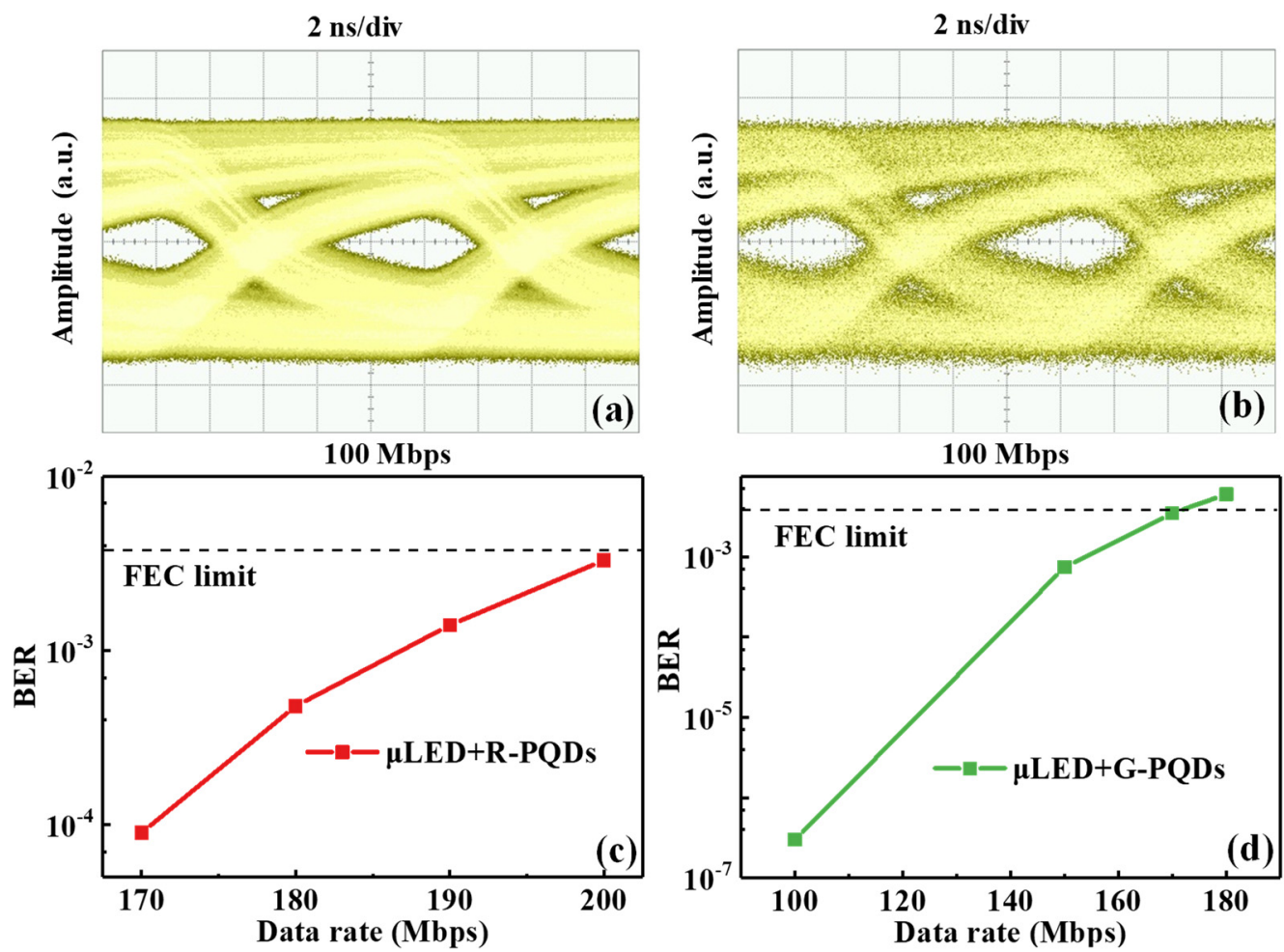

Figure 7. Eye diagrams versus data rates at $100 \mathrm{Mbps}$ of (a) $\mu \mathrm{LED}+\mathrm{R}-\mathrm{PQD}$ and (b) $\mu \mathrm{LED}+\mathrm{G}-\mathrm{PQDs}$. BER at different data rates of (c) $\mu$ LED + R-PQDs and (d) $\mu$ LED + G-PQDs. The dashed line shows the FEC threshold.

To verify high-efficiency illumination and high-speed wireless communication at the same time, the characteristics of the WL-VLC system based on GaN-based white-light LED were further studied. Based on the abovementioned systems, the green light was emitted from the G-PQDs under excitation of the blue light from $\mu \mathrm{LED}$, and then the mixed light was used to excite the R-PQDs. Consequently, as the blue light, green light, and red light merged, the white light was obtained. The performances of the white-light system were measured and discussed in our further experiments.

As exhibited in Figure 8a, the CIE color coordinates of the WL-VLC system were $(0.3327,0.3114)$ and the color temperature was $5474 \mathrm{~K}$. Note that compared with the CIE of $(0.27,0.30)$ in our previous study [38], a better-quality white light of our WL-VLC system 
was generated, which is very close to the CIE of $(0.33,0.33)$ for standard white light. As presented in Figure $8 \mathrm{~b}$, the maximum bandwidth achieved for the proposed WL-VLC system was $57.5 \mathrm{MHz}$. The eye diagram of the WL-VLC system at $90 \mathrm{Mbps}$ is shown in the inset of Figure $8 \mathrm{~b}$. The above results reveal that the WL-VLC system proposed in this work implemented a high-performance SSL and VLC based on the white-light GaN-based $\mu$ LED. Compared with the monochromatic light system, the eye diagram is noisy and relatively close. Consequently, substantial efforts will be made to further optimize the InGaN- $\mu L E D s$ and PQDs to achieve high bandwidth, high light-output power, and better linearity.
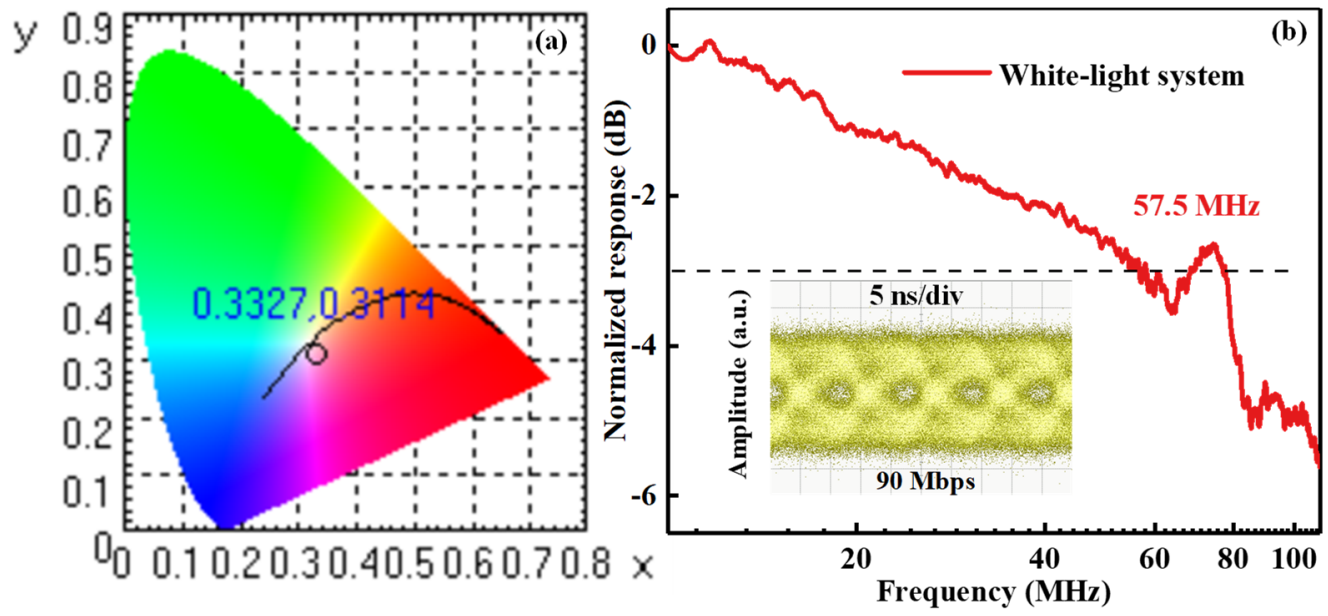

Figure 8. (a) CIE color coordinates and (b) frequency responses of the white light used in the WL-VLC system. The $-3 \mathrm{~dB}$ modulation bandwidth is marked by a dashed line. Inset: the eye diagram versus the data rate of the system at 90 Mbps.

\section{Conclusions}

In this study, a WL-VLC system based on white-light GaN-based $\mu$ LEDs with green and red PQDs as color converters was proposed and demonstrated experimentally for both communication and illumination. The essential optical and electrical performances of monochromatic light from the InGaN- $\mu$ LEDs, G-PQDs, and R-PQDs, as well as the white light, were studied. The corresponding communication and illumination performances were systematically investigated in detail. We achieved the maximum bandwidths of $162 \mathrm{MHz}, 90 \mathrm{MHz}, 64 \mathrm{MHz}$, and $57.5 \mathrm{MHz}$ for InGaN- $\mu$ LEDs, R-PQDs, G-PQDs, and white-light in our WL-VLC system, respectively. High-quality white light was generated which possessed CIE of $(0.3327,0.3114)$ and a correlated color temperature of $5474 \mathrm{~K}$. It is worth noting that using R-PQDs and G-PQDs as color converters, the available CIE of $(0.3327,0.3114)$ is closer to the CIE of $(0.33,0.33)$ for standard white light, compared with that $(0.27,0.30)$ of white light using yellow PQDs as color converters in our previous study. These results shed new light on the potential of InGaN- $\mu$ LEDs combined with PQDs for both high-speed VLC and high-efficiency SSL.

Supplementary Materials: The following are available online at https:/ / www.mdpi.com/article/10 $.3390 /$ nano12040627/s1. Figure S1: (a) J-V and (b) L-I characteristics of square InGaN- $\mu$ LEDs with different sizes. Figure S2: The normalized EL spectra of the square $\mu$ LED with a side length of $80 \mu \mathrm{m}$ under different applied voltages. Figure S3: The normalized response of the square $\mu$ LED with a side length of $80 \mu \mathrm{m}$ under a current of $70 \mathrm{~mA}$. The dashed line represents the forward error correction (FEC) threshold.

Author Contributions: Conceptualization, P.T., R.G., L.W. and X.L.; methodology, X.L. and S.M.; formal analysis, X.L., L.T. and S.M.; investigation, X.L., L.T. and D.S.; writing-original draft preparation, X.L. and L.T.; writing-review and editing, X.L., L.T., Z.C., Z.S., P.Y., J.Y., T.Z. and T.T.; supervision, P.T., R.G. and L.W.; project administration, X.L. and P.T.; funding acquisition, X.L., P.T., R.G. and L.W. All authors have read and agreed to the published version of the manuscript. 
Funding: This research was funded by the National Key Research and Development Program of China (2021YFE0105300), Key Technologies R\&D Program of Huzhou City Science and Technology Project (2020GG03), Natural Science Research of Jiangsu Higher Education Institutions of China (20KJB510014), NJUPTSF (NY220078), the Foundation of Jiangsu Provincial Double-Innovation Doctor Program (JSSCBS20210522), National Natural Science Foundation of China (61974031, 61904087, 61974062), Fudan University-CIOMP Joint Fund (FC2020-001).

Institutional Review Board Statement: Not applicable.

Informed Consent Statement: Not applicable.

Data Availability Statement: Data underlying the results presented in this paper are not publicly available at this time, but may be obtained from the authors upon reasonable request. The data that support the findings of this study are available upon reasonable request from the authors.

Conflicts of Interest: The authors declare no conflict of interest.

\section{References}

1. Orton, J.W.; Foxon, C.T. Group III nitride semiconductors for short wavelength light-emitting devices. Rep. Prog. Phys. 1998, 61, 1. [CrossRef]

2. Mukai, T. Recent progress in group-III nitride light-emitting diodes. IEEE J. Sel. Top. Quantum Electron. 2002, 8, 264-270. [CrossRef]

3. Akasaki, I.; Amano, H. Crystal growth and conductivity control of group III nitride semiconductors and their application to short wavelength light emitters. Jpn. J. Appl. Phys. 1997, 36, 5393. [CrossRef]

4. Amano, H.; Sawaki, N.; Akasaki, I.; Toyoda, Y. Metalorganic vapor phase epitaxial growth of a high quality GaN film using an AlN buffer layer. Appl. Phys. Lett. 1986, 48, 353-355. [CrossRef]

5. Duboz, J.Y. GaN as seen by the industry. Phys. Status Solidi A 1999, 176, 5-14. [CrossRef]

6. Jones, E.A.; Wang, F.F.; Costinett, D. Review of commercial GaN power devices and GaN-based converter design challenges. IEEE J. Emerg. Sel. Top. Power Electron. 2016, 4, 707-719. [CrossRef]

7. Zhu, D.; Wallis, D.; Humphreys, C. Prospects of III-nitride optoelectronics grown on Si. Rep. Prog. Phys. 2013, 76, 106501. [CrossRef]

8. Li, G.; Wang, W.; Yang, W.; Lin, Y.; Wang, H.; Lin, Z.; Zhou, S. GaN-based light-emitting diodes on various substrates: A critical review. Rep. Prog. Phys. 2016, 79, 056501. [CrossRef]

9. Nakamura, S.; Senoh, M.; Mukai, T. High-power InGaN/GaN double-heterostructure violet light emitting diodes. Appl. Phys. Lett. 1993, 62, 2390-2392. [CrossRef]

10. Li, J.; Wang, J.; Yi, X.; Liu, Z.; Wei, T.; Yan, J.; Xue, B. Applications of LEDs. In III-Nitrides Light Emitting Diodes: Technology and Applications; Springer: Singapore, 2020; pp. 229-251, ISBN 978-981-10-3755-9.

11. Sijbom, H.F.; Verstraete, R.; Joos, J.J.; Poelman, D.; Smet, P.F. $\mathrm{K}_{2} \mathrm{SiF}_{6}: \mathrm{Mn}^{4+}$ as a red phosphor for displays and warm-white LEDs: A review of properties and perspectives. Opt. Mater. Express 2017, 7, 3332-3365. [CrossRef]

12. Zhao, M.; Zhang, Q.; Xia, Z. Narrow-band emitters in LED backlights for liquid-crystal displays. Mater. Today 2020, 40, 246-265. [CrossRef]

13. Lin, J.; Jiang, H. Development of microLED. Appl. Phys. Lett. 2020, 116, 100502. [CrossRef]

14. Zhou, X.; Tian, P.; Sher, C.-W.; Wu, J.; Liu, H.; Liu, R.; Kuo, H.-C. Growth, transfer printing and colour conversion techniques towards full-colour micro-LED display. Prog. Quantum Electron. 2020, 71, 100263. [CrossRef]

15. Kim, T.-I.; McCall, J.G.; Jung, Y.H.; Huang, X.; Siuda, E.R.; Li, Y.; Song, J.; Song, Y.M.; Pao, H.A.; Kim, R.-H. Injectable, cellular-scale optoelectronics with applications for wireless optogenetics. Science 2013, 340, 211-216. [CrossRef] [PubMed]

16. McKendry, J.J.; Green, R.P.; Kelly, A.; Gong, Z.; Guilhabert, B.; Massoubre, D.; Gu, E.; Dawson, M.D. High-speed visible light communications using individual pixels in a micro light-emitting diode array. IEEE Photonics Technol. Lett. 2010, 22, 1346-1348. [CrossRef]

17. Lin, R.; Liu, X.; Zhou, G.; Qian, Z.; Cui, X.; Tian, P. InGaN Micro-LED Array Enabled Advanced Underwater Wireless Optical Communication and Underwater Charging. Adv. Opt. Mater. 2021, 9, 2002211. [CrossRef]

18. Zhu, S.; Qiu, P.; Qian, Z.; Shan, X.; Wang, Z.; Jiang, K.; Sun, X.; Cui, X.; Zhang, G.; Li, D. 2 Gbps free-space ultraviolet-C communication based on a high-bandwidth micro-LED achieved with pre-equalization. Opt. Lett. 2021, 46, 2147-2150. [CrossRef]

19. Liu, X.; Lin, R.; Chen, H.; Zhang, S.; Qian, Z.; Zhou, G.; Chen, X.; Zhou, X.; Zheng, L.; Liu, R.; et al. High-Bandwidth InGaN Self-Powered Detector Arrays toward MIMO Visible Light Communication Based on Micro-LED Arrays. ACS Photonics 2019, 6, 3186-3195. [CrossRef]

20. Islim, M.S.; Ferreira, R.X.; He, X.; Xie, E.; Videv, S.; Viola, S.; Watson, S.; Bamiedakis, N.; Penty, R.V.; White, I.H. Towards 10 Gb/s orthogonal frequency division multiplexing-based visible light communication using a GaN violet micro-LED. Photonics Res. 2017, 5, A35-A43. [CrossRef]

21. Xie, E.; Bian, R.; He, X.; Islim, M.S.; Chen, C.; McKendry, J.J.; Gu, E.; Haas, H.; Dawson, M.D. Over 10 Gbps VLC for long-distance applications using a GaN-based series-biased micro-LED array. IEEE Photonics Technol. Lett. 2020, 32, 499-502. [CrossRef] 
22. Carreira, J.; Griffiths, A.; Xie, E.; Guilhabert, B.; Herrnsdorf, J.; Henderson, R.; Gu, E.; Strain, M.; Dawson, M.D. Direct integration of micro-LEDs and a SPAD detector on a silicon CMOS chip for data communications and time-of-flight ranging. Opt. Express 2020, 28, 6909-6917. [CrossRef]

23. Elgala, H.; Mesleh, R.; Haas, H.; Pricope, B. OFDM visible light wireless communication based on white LEDs. In Proceedings of the 2007 IEEE 65th Vehicular Technology Conference-VTC2007-Spring, Dublin, Ireland, 22-25 April 2007; pp. $2185-2189$.

24. Grubor, J.; Randel, S.; Langer, K.-D.; Walewski, J.W. Broadband Information Broadcasting Using LED-Based Interior Lighting. J. Lightwave Technol. 2008, 26, 3883-3892. [CrossRef]

25. Hoa Le, M.; O’Brien, D.; Faulkner, G.; Lubin, Z.; Kyungwoo, L.; Daekwang, J.; YunJe, O.; Eun Tae, W. 100-Mb/s NRZ Visible Light Communications Using a Postequalized White LED. IEEE Photonics Technol. Lett. 2009, 21, 1063-1065. [CrossRef]

26. Li, Y.; Feng, J.; Sun, H. Perovskite quantum dots for light-emitting devices. Nanoscale 2019, 11, 19119-19139. [CrossRef] [PubMed]

27. Yang, B.; Zheng, F.; Mei, S.; Chen, Z.; Xie, Y.; Dai, H.; Wei, X.; Zhang, W.; Xie, F.; Ju, J.; et al. Component regulation and crystallization mechanism of $\mathrm{CsPbBr}_{3} / \mathrm{Cs}_{4} \mathrm{PbBr}_{6}$ perovskite composite quantum dots-embedded borosilicate glass for light emitting application. Appl. Surf. Sci. 2020, 512, 145655. [CrossRef]

28. Shen, L.; Zhang, Z.; Zhao, Y.; Yang, H.; Yuan, L.; Chen, Y.; Xiang, W.; Liang, X. Synthesis and optical properties of novel mixed-metal cation $\mathrm{CsPb}_{1-x} \mathrm{Ti}_{\mathrm{x}} \mathrm{Br}_{3}$-based perovskite glasses for W-LED. J. Am. Ceram. Soc. 2019, 103, 382-390. [CrossRef]

29. Wang, B.; Zhang, S.; Liu, B.; Li, J.; Cao, B.; Liu, Z. Stable CsPbBr $3: \mathrm{Sn} @ S i O_{2}$ and $\mathrm{Cs}_{4} \mathrm{PbBr}_{6}: \mathrm{Sn}_{\mathrm{SSiO}}$ Core-Shell Quantum Dots with Tunable Color Emission for Light-Emitting Diodes. ACS Appl. Nano Mater. 2020, 3, 3019-3027. [CrossRef]

30. He, H.; Mei, S.; Chen, Z.; Liu, S.; Wen, Z.; Cui, Z.; Yang, D.; Zhang, W.; Xie, F.; Yang, B. Thioacetamide-ligand-mediated synthesis of $\mathrm{CsPbBr}_{3}-\mathrm{CsPbBr}_{3}$ homostructured nanocrystals with enhanced stability. J. Mater. Chem. C 2021, 9, 11349-11357. [CrossRef]

31. Chen, Z.; Mei, S.; He, H.; Wen, Z.; Cui, Z.; Yang, B.; Yang, D.; Zhang, W.; Xie, F.; Zou, J. Rapid large-scale synthesis of highly emissive solid-state metal halide perovskite quantum dots across the full visible spectrum. Opt. Laser Technol. 2021, 143, 107369. [CrossRef]

32. Dursun, I.; Shen, C.; Parida, M.R.; Pan, J.; Sarmah, S.P.; Priante, D.; Alyami, N.; Liu, J.; Saidaminov, M.I.; Alias, M.S.; et al Perovskite Nanocrystals as a Color Converter for Visible Light Communication. ACS Photonics 2016, 3, 1150-1156. [CrossRef]

33. Liang, S.; Lu, Z.; Ding, X.; Li, J.; Tang, Y.; Li, Z.; Yu, B. Perovskite liquid quantum dots as a color converter for LD-based white lighting system for visible light communication. In Proceedings of the 2019 16th China International Forum on Solid State Lighting \& 2019 International Forum on Wide Bandgap Semiconductors China, Shenzhen, China, 25-27 November 2019; pp. 277-279.

34. Tsao, J.Y.; Crawford, M.H.; Coltrin, M.E.; Fischer, A.J.; Koleske, D.D.; Subramania, G.S.; Wang, G.T.; Wierer, J.J.; Karlicek, R.F. Toward Smart and Ultra-efficient Solid-State Lighting. Adv. Opt. Mater. 2014, 2, 809-836. [CrossRef]

35. Liu, X.; Tian, P.; Wei, Z.; Yi, S.; Huang, Y.; Zhou, X.; Qiu, Z.-J.; Hu, L.; Fang, Z.; Cong, C. Gbps long-distance real-time visible light communications using a high-bandwidth GaN-based micro-LED. IEEE Photonics J. 2017, 9, 1-9. [CrossRef]

36. Tian, P.; Wu, Z.; Liu, X.; Fang, Z.; Zhang, S.; Zhou, X.; Liu, K.; Liu, M.-G.; Chen, S.-J.; Lee, C.-Y.; et al. Large-signal modulation characteristics of a GaN-based micro-LED for Gbps visible-light communication. Appl. Phys Express 2018, 11, 044101. [CrossRef]

37. Leitao, M.F.; Islam, M.S.; Yin, L.; Viola, S.; Watson, S.; Kelly, A.; Li, X.; Yu, D.; Zeng, H.; Videv, S.; et al. MicroLED-pumped perovskite quantum dot color converter for visible light communications. In Proceedings of the 2017 IEEE Photonics Conference (IPC), Orlando, FL, USA, 1-5 October 2017; pp. 68-69.

38. Mei, S.; Liu, X.; Zhang, W.; Liu, R.; Zheng, L.; Guo, R.; Tian, P. High-Bandwidth White-Light System Combining a Micro-LED with Perovskite Quantum Dots for Visible Light Communication. ACS Appl. Mater. Interfaces 2018, 10, 5641-5648. [CrossRef]

39. Tian, P.; Liu, X.; Yi, S.; Huang, Y.; Zhang, S.; Zhou, X.; Hu, L.; Zheng, L.; Liu, R. High-speed underwater optical wireless communication using a blue GaN-based micro-LED. Opt. Express 2017, 25, 1193-1201. [CrossRef]

40. Tian, P.; McKendry, J.J.; Gong, Z.; Zhang, S.; Watson, S.; Zhu, D.; Watson, I.M.; Gu, E.; Kelly, A.E.; Humphreys, C.J. Characteristics and applications of micro-pixelated GaN-based light emitting diodes on Si substrates. J. Appl. Phys. 2014, 115, 033112. [CrossRef]

41. Tian, P.; McKendry, J.J.; Gong, Z.; Guilhabert, B.; Watson, I.M.; Gu, E.; Chen, Z.; Zhang, G.; Dawson, M.D. Size-dependent efficiency and efficiency droop of blue InGaN micro-light emitting diodes. Appl. Phys. Lett. 2012, 101, 231110. [CrossRef]

42. Tian, P.; McKendry, J.J.D.; Herrnsdorf, J.; Watson, S.; Ferreira, R.; Watson, I.M.; Gu, E.; Kelly, A.E.; Dawson, M.D. Temperaturedependent efficiency droop of blue InGaN micro-light emitting diodes. Appl. Phys. Lett. 2014, 105, 171107. [CrossRef]

43. Zhang, W.; Yang, W.; Zhong, P.; Mei, S.; Zhang, G.; Chen, G.; He, G.; Guo, R. Spectral optimization of color temperature tunable white LEDs based on perovskite quantum dots for ultrahigh color rendition. Opt. Mater. Express 2017, 7, 3065-3076. [CrossRef]

44. Gong, Z.; Jin, S.; Chen, Y.; McKendry, J.; Massoubre, D.; Watson, I.M.; Gu, E.; Dawson, M.D. Size-dependent light output, spectral shift, and self-heating of $400 \mathrm{~nm}$ InGaN light-emitting diodes. J. Appl. Phys. 2010, 107, 013103. [CrossRef]

45. Tian, P.; Althumali, A.; Gu, E.; Watson, I.M.; Dawson, M.D.; Liu, R. Aging characteristics of blue InGaN micro-light emitting diodes at an extremely high current density of $3.5 \mathrm{kA} \mathrm{cm}^{-2}$. Semicond. Sci. Tech. 2016, 31, 045005. [CrossRef]

46. Trindade, A.; Guilhabert, B.; Xie, E.; Ferreira, R.; McKendry, J.; Zhu, D.; Laurand, N.; Gu, E.; Wallis, D.; Watson, I. Heterogeneous integration of gallium nitride light-emitting diodes on diamond and silica by transfer printing. Opt. Express 2015, 23, 9329-9338. [CrossRef] [PubMed] 